\title{
Synthesis and Redox Reactivity of a Phosphine-ligated Dichromium Paddlewheel
}

\author{
Reed J. Eisenhart, ${ }^{\dagger}$ Rebecca K. Carlson, ${ }^{\dagger, \dagger}$ Kelsey M. Boyle, ${ }^{\dagger}$ Laura Gagliardi, ${ }^{\dagger, \dagger}$ Connie C. Lu ${ }^{*}$, \\ †Department of Chemistry, University of Minnesota, 207 Pleasant Street SE, Minneapolis, Minnesota \\ 55455-0431, USA; ${ }^{*}$ Supercomputing Institute, and Chemical Theory Center, University of Minnesota \\ Minneapolis, Minnesota, 55455, USA. \\ *corresponding author: clu@umn.edu
}

\begin{abstract}
A pentadentate ligand platform, bis[2-(diispropylphosphino-methylamino)phenyl]ether (1), abbreviated as $\mathrm{H}_{2}$ (PNONP), is introduced that enables the isolation of homodinuclear chromium complexes. In a one-step metalation using $\mathrm{Cr}(\mathrm{III})$ and $\mathrm{Cr}(\mathrm{II})$ chloride reagents, the bimetallic compounds, $[\mathrm{Cr}(\mu-\mathrm{Cl})(\mathrm{PNONP})]_{2}(\mathbf{2})$ and $[\mathrm{Cr}(\mathrm{PNONP})]_{2}(3)$, respectively, were synthesized. These complexes have been characterized by X-ray diffraction, NMR spectroscopy, cyclic voltammetry, magnetometry, UV-vis-NIR spectroscopy, combustion analysis, and computational methods. Complex 3 has a reasonably short $\mathrm{Cr}-\mathrm{Cr}$ bond length of 2.1342(5) $\AA$. Quantum chemical calculations support a diradical singlet ground-state with a formal triple bond between the chromium centers. By cyclic voltammetry, 3 exhibits two reversible oxidations at $E_{1 / 2}=-472$ and $-753 \mathrm{mV}$ versus $\mathrm{FeCp}_{2}{ }^{0 /+}$. The one- and two-electron oxidized analogues, $\mathbf{3}^{+}$and $\mathbf{3}^{2+}$, were generated in situ via chemical oxidation using ferrocenium. Based on in situ characterization of $\mathbf{3}^{+}$and $\mathbf{3}^{2+}$, we hypothesize the oxidations are metal-based to yield $\mathrm{Cr}_{2}{ }^{5+}$ and $\mathrm{Cr}_{2}{ }^{6+}$ cores, respectively.
\end{abstract}

Keywords: dichromium, metal-metal multiple bond, phosphine, dinuclear, homobimetallic

\section{Introduction}

Dichromium paddlewheels feature prominently in the history of metal-metal multiple bonds.[1-5] Despite the vast number of multiply bonded $\mathrm{Cr}_{2}{ }^{4+}$ paddlewheels, only one species, a dichromium tetraguanidinate complex, $\mathrm{Cr}_{2}(\mathrm{DPPC})_{4}$ (where DPPC is $(\mathrm{PhN})_{2} \mathrm{CN}\left(\mathrm{CH}_{2}\right)_{4}$; Figure 1, a), was reported to exhibit reversible oxidation processes

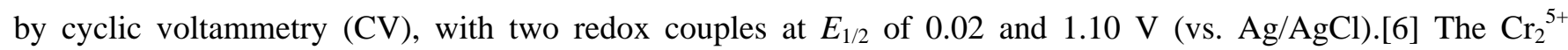
analogue was subsequently isolated and characterized by X-ray diffraction.[7] A high-field (W-band) EPR spectroscopic study proved definitively that the unpaired spin resided at chromium, thus supporting the formation of an oxidized $\mathrm{Cr}_{2}{ }^{5+}$ core. The unique redox behavior was attributed to the extreme $\sigma$ and $\pi$ basicity of the guanidinate ligands. Recently, a $\mathrm{Cr}_{2}{ }^{6+}$ species was isolated via oxidation of a $\mathrm{Cr}_{2}{ }^{4+}$ paddlewheel, $\mathrm{Cr}_{2}(\mathrm{dpa})_{4}($ where dpa is dipyridylamide) using two equiv. of AgOTf.[8] The solid-state structure revealed a complete rupture of the 
$\mathrm{Cr}-\mathrm{Cr}$ bond with a long $\mathrm{Cr} \cdots \mathrm{Cr}$ distance of 3.197(3) $\AA$, attesting to the challenge in isolating higher valent $\mathrm{Cr}_{2}{ }^{5+}$ and $\mathrm{Cr}_{2}{ }^{6+}$ paddlewheels (Figure $1, \mathbf{b}$ ).

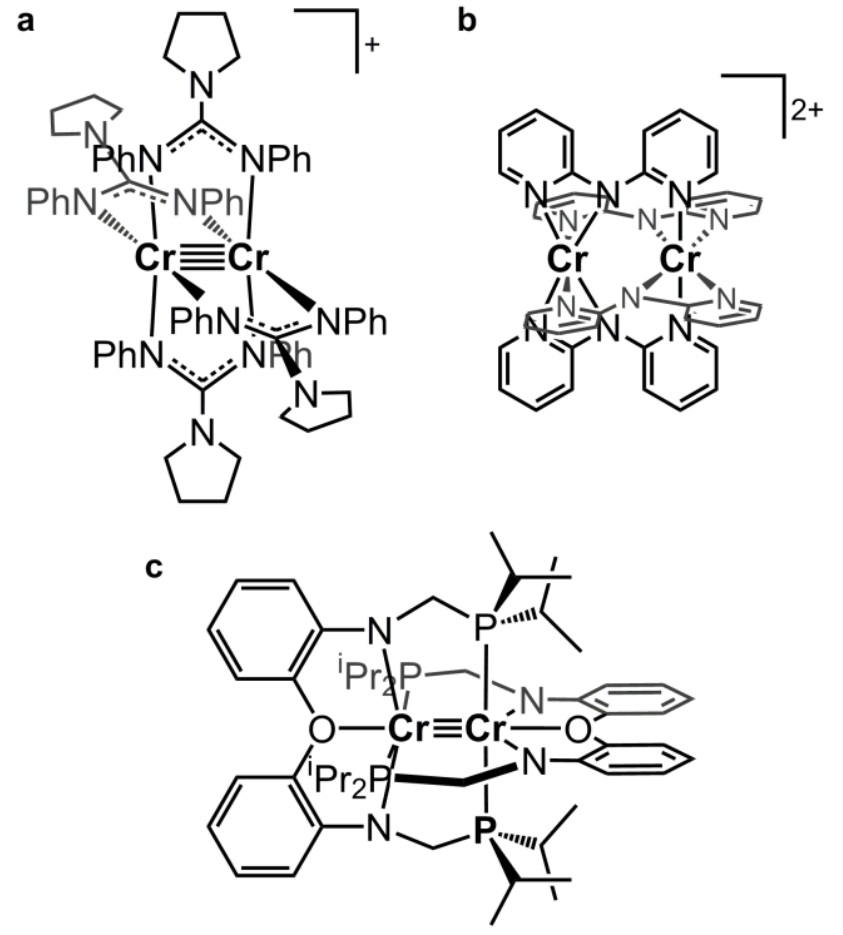

Figure 1. Dichromium paddlewheels

Herein, we report $\mathrm{a}_{2}{ }^{4+}$ paddlewheel supported by new pentadentate ligand that comprises mixed phosphine, amide, and ether donors. The ligand binds dichromium in a 2:1 ratio, thus saturating all the available coordination sites of the $\mathrm{Cr}_{2}^{4+}$ unit (Figure 1, c). Phosphine ligands are rare in the coordination chemistry of multiply-bonded dichromium. To our knowledge, the only structurally characterized complex is $\mathrm{Li}_{2}\left[\mathrm{Cr}_{2}\left(\mathrm{CH}_{2} \mathrm{PMe}_{2}\right)_{6}\right]$.[9] This is in contrast to the heavier Group 6 metals, Mo and $\mathrm{W}$, for which numerous examples of phosphine-supported multiply bonded cores have been isolated, including a family of $\mathrm{M}_{2}\left(\mathrm{PR}_{3}\right)_{4} \mathrm{X}_{4}$

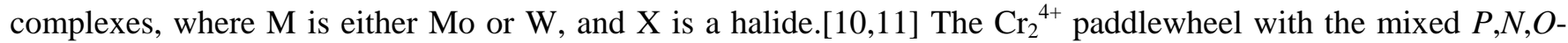
donor set was characterized by a suite of physical methods, including X-ray diffraction, cyclic voltammetry, and magnetic susceptibility measurements. Theoretical studies were also conducted to elucidate its electronic structure and bonding. The combined physical and theoretical data support a triply bonded dichromium core that is capable of undergoing two one-electron oxidations. The oxidized counterparts were generated in situ, and preliminary characterization suggests metal-based oxidations to $\mathrm{Cr}_{2}{ }^{5+}$ and $\mathrm{Cr}_{2}{ }^{6+}$ species. 


\section{Experimental Section}

\subsection{General Procedures}

All manipulations were performed under a dinitrogen atmosphere inside a glovebox. Standard solvents were deoxygenated by sparging with $\mathrm{N}_{2}$ and dried by passing them through activated alumina columns of an SG Water solvent purification system. $\mathrm{Bis}\left(2\right.$-amino-phenyl)ether and $\left[\mathrm{FeCp}_{2}\right]\left[\mathrm{BAr}^{\mathrm{F}}{ }_{4}\right]$ were prepared according to literature methods.[12,13] Deuterated solvents were purchased from Cambridge Isotope Laboratories, dried over calcium hydride and distilled, degassed via freeze-pump- thaw cycles, and stored over activated $4 \AA$ molecular sieves. All reagents were purchased from Aldrich or Strem and used without further purification. Elemental analyses were performed by Complete Analysis Laboratories (Parsippany, NJ) and Robertson Microlit Laboratories (Ledgewood, NJ). ${ }^{1} \mathrm{H}$ NMR spectra were recorded on a Bruker $500 \mathrm{MHz}$, or a Varian 300 or $500 \mathrm{MHz}$ spectrometer at rt unless otherwise stated. All ${ }^{1} \mathrm{H}$ and ${ }^{13} \mathrm{C}$ NMR spectra are referenced to the internal solvent residual. Variable temperature NMR experiments were performed on a Varian $300 \mathrm{MHz}$ spectrometer. The temperature of the NMR probe was calibrated against an external methanol standard. UV-vis-NIR spectra were collected on a HP8453 (190-1000 $\mathrm{nm}$ ) diode array spectrophotometer. Low temperature UV-vis-NIR experiments were performed using an Unisoku low temperature UV-vis cell holder. Cyclic voltammetry was conducted using a $\mathrm{CH}$ Instruments 600 electrochemical analyzer. The one-cell setup utilized a glassy carbon working electrode, Pt wire counter electrode, and $\mathrm{Ag} / \mathrm{AgNO}_{3}$ reference electrode in $\mathrm{CH}_{3} \mathrm{CN}$. Analyte solutions were prepared in a THF solution of $0.4 \mathrm{M}$ $\left[{ }^{\mathrm{n}} \mathrm{Bu}_{4} \mathrm{~N}\right]\left[\mathrm{PF}_{6}\right]$ and referenced internally to the $\mathrm{FeCp}_{2}{ }^{0 /+}$ redox couple. Perpendicular-mode X-band EPR spectra were recorded at $20 \mathrm{~K}$ with a Bruker ESP 300 spectrometer equipped with an Oxford ESR 910 liquid helium cryostat and an Oxford temperature controller. X-band EPR spectra were simulated by using EPR program (version W95) written by Professor Frank Neese (MPI-CEC, Mülheim, Germany). Magnetic susceptibility of 2 was determined by the Evans' Method,[14] measured in $\mathrm{C}_{6} \mathrm{D}_{6}$ at $300 \mathrm{~K}$ using a Bruker $500 \mathrm{MHz}$ spectrometer, and a sealed glass capillary containing 2:1 $\mathrm{C}_{6} \mathrm{D}_{6}: \mathrm{C}_{6} \mathrm{H}_{6}$. Magnetic susceptibility data were measured from powder samples of solid material over the temperature range 2-290 K using a SQUID susceptometer with a field of $1.0 \mathrm{~T}$ (MPMS-7, Quantum Design, calibrated with a standard palladium reference sample, error $<2 \%$ ). The experimental data were corrected for underlying diamagnetism using tabulated Pascal's constants $\left(\chi_{\text {dia }}<0\right)[15,16]$ as well as for temperature-independent paramagnetism $\left(\chi_{\text {TIP }}>0\right)$.[17] Specifically, the value of $\chi_{\text {TIP }}$ used for 3 was $180 \times 10^{-6}$ emu.

\subsection{Preparation of bis[2-(diispropylphosphino-methylamino)phenyl]ether, $\mathrm{H}_{2} \mathrm{PNONP}(\mathbf{1})$}

A mixture of paraformaldehyde $(0.512 \mathrm{~g}, 16.9 \mathrm{mmol}),{ }^{i} \mathrm{Pr}_{2} \mathrm{PH}(2.00 \mathrm{~g}, 16.9 \mathrm{mmol})$ and $15 \mathrm{~mL} n$-hexane was stirred at $55^{\circ} \mathrm{C}$ for $3 \mathrm{~h}$. The solvent was removed in vacuo and to the resulting oil was added $15 \mathrm{~mL}$ THF and bis(2-aminophenyl)ether $(1.74 \mathrm{~g}, 8.67 \mathrm{mmol})$. This reaction mixture was stirred for $12 \mathrm{~h}$ at $65^{\circ} \mathrm{C}$, and then the solvent was removed in vacuo. The crude product was dissolved in $20 \mathrm{~mL}$ pentane, filtered, and added to the top of a short silica plug. The plug was washed with $60 \mathrm{~mL}$ hexane, and the product eluted with $60 \mathrm{~mL}$ of a 9:1 hexane/THF mixture. Evaporation of the eluent in vacuo yielded a colorless oil ( $3.12 \mathrm{~g}, 6.77 \mathrm{mmol}, 78 \%$ yield). ${ }^{1} \mathrm{H}$ NMR (500 $\left.\mathrm{MHz}, \mathrm{C}_{6} \mathrm{D}_{6}\right) \partial 7.03$ (t, J=11 Hz, 2H), 6.84 (d, J=13 Hz, 2H), 6.77 (d, J=13 Hz, 2H), 6.57 (t, J=11 Hz, 2H), 4.45 (br, $2 \mathrm{H}, \mathrm{NH}), 3.13(\mathrm{dd}, J=1.5 \& 5 \mathrm{~Hz}, 4 \mathrm{H}), 1.60$ (septet of d, $J=3 \& 7 \mathrm{~Hz}, 4 \mathrm{H}), 0.99$ (dd, $J=7 \& 14 \mathrm{~Hz}), 0.95$ (dd, $J=7$

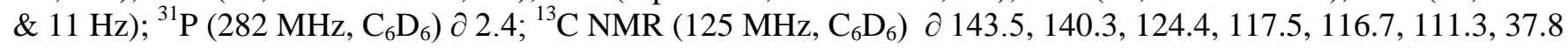
$(\mathrm{d}, J=18 \mathrm{~Hz}), 22.6(\mathrm{~d}, J=14 \mathrm{~Hz}), 20.0(\mathrm{~d}, J=12.5 \mathrm{~Hz}), 18.8(\mathrm{~d}, J=12.5 \mathrm{~Hz})$. ESI-MS-TOF $\mathrm{m} / z:[\mathrm{M}+\mathrm{Na}]^{+}$calcd for $\mathrm{C}_{26} \mathrm{H}_{42} \mathrm{~N}_{2} \mathrm{OP}_{2} \mathrm{Na}$ 483.2665; found, 483.2718 .

\subsection{Preparation of $[\mathrm{Cr}(\mu-\mathrm{Cl})(\mathrm{PNONP})]_{2}(\mathbf{2})$}

To a frozen $\mathrm{Et}_{2} \mathrm{O}$ solution of $1(92.0 \mathrm{mg}, 0.200 \mathrm{mmol}),{ }^{n} \mathrm{BuLi}(2.50 \mathrm{M}$ in hexanes, $0.160 \mathrm{~mL}, 0.400 \mathrm{mmol})$ was added dropwise. The stirring reaction was allowed to warm to rt immediately and was stirred for an additional $2 \mathrm{~h}$. After removing the solvent in vacuo, the crude residue was dissolved in $10 \mathrm{~mL}$ THF and added to a stirring THF 
slurry of $\mathrm{CrCl}_{3}(\mathrm{THF})_{3}(75.0 \mathrm{mg}, 0.200 \mathrm{mmol})$ at $-50^{\circ} \mathrm{C}$. Upon warming to $\mathrm{rt}$ and stirring overnight the solvent was removed in vacuo. The crude residue was washed with $10 \mathrm{ml}$ pentane, dissolved in $15 \mathrm{~mL}$ benzene, and filtered through a pipette containing a plug of glass filter paper. The filtrate was reduced in vacuo to yield a salmoncolored solid (53.8 mg, $0.107 \mathrm{mmol}, 55 \%$ yield). ${ }^{1} \mathrm{H}$ NMR $\left(500 \mathrm{MHz}, \mathrm{C}_{6} \mathrm{D}_{6}\right) \partial 68,20,16.7,1.9,-4.7,-8.4,-17.9$, -26.6. UV-vis-NIR (THF) $\lambda_{\max }, \mathrm{nm}\left(\varepsilon, \mathrm{M}^{-1} \mathrm{~cm}^{-1}\right)$ : 430 (1,100); $680 \mathrm{sh}$ (150); $850 \mathrm{sh}(80)$. Evans' method $\left(\mathrm{C}_{6} \mathrm{D}_{6}\right)$ : $\mu_{\text {eff }}=3.87 \mu_{\mathrm{B}}$. Anal. Calcd for $2, \mathrm{C}_{52} \mathrm{H}_{80} \mathrm{~N}_{4} \mathrm{O}_{2} \mathrm{P}_{4} \mathrm{Cr}_{2} \mathrm{Cl}_{2}$ : C 57.19, H 7.38, N 5.13. Found: C 56.07, H 7.09, N 4.89.

\subsection{Preparation of $[\mathrm{Cr}(\mathrm{PNONP})]_{2}(\mathbf{3})$}

To a frozen $\mathrm{Et}_{2} \mathrm{O}$ solution of 1 (230 mg, $\left.0.50 \mathrm{mmol}\right),{ }^{n} \mathrm{BuLi}(2.50 \mathrm{M}$ in hexanes, $0.400 \mathrm{~mL}, 1.00 \mathrm{mmol})$ was added dropwise. The stirring reaction was allowed to warm to rt immediately and was stirred for an additional $2 \mathrm{~h}$. After removing the solvent in vacuo, the crude residue was dissolved in $10 \mathrm{~mL}$ THF and added to a stirring THF slurry of $\mathrm{CrCl}_{2}(61.5 \mathrm{mg}, 0.500 \mathrm{mmol})$ at $-50^{\circ} \mathrm{C}$. Upon warming to $\mathrm{rt}$ and stirring overnight the solvent was removed in vacuo. The resulting solid was washed with $20 \mathrm{~mL}$ pentane, dissolved in $15 \mathrm{~mL}$ benzene, filtered and dried in vacuo to yield a bronze-colored crystalline solid (107 mg, $0.105 \mathrm{mmol}, 62 \%$ yield). ${ }^{1} \mathrm{H}$ NMR $\left(500 \mathrm{MHz}, \mathrm{C}_{6} \mathrm{D}_{6}\right) \partial$ $7.43(\mathrm{~d}, J=8 \mathrm{~Hz}, 2 \mathrm{H}), 7.07(\mathrm{t}, J=8 \mathrm{~Hz}, 2 \mathrm{H}), 6.65(\mathrm{~d}, J=8 \mathrm{~Hz}, 2 \mathrm{H}), 6.36$ (t, $J=8 \mathrm{~Hz}, 2 \mathrm{H}), 4.28$ (s, 4H), 2.19 (septet, $J=7 \mathrm{~Hz}), 1.05(\mathrm{~d}, J=6 \mathrm{~Hz}, 12 \mathrm{H}), 0.77(\mathrm{~d}, J=5 \mathrm{~Hz}, 12 \mathrm{H}) .{ }^{31} \mathrm{P}\left(282 \mathrm{MHz}, \mathrm{C}_{6} \mathrm{D}_{6}\right) \partial 19.8 ;{ }^{13} \mathrm{C} \mathrm{NMR}\left(125 \mathrm{MHz}, \mathrm{C}_{6} \mathrm{D}_{6}\right) \partial$ 151.6, 144.6, 124.2, 113.2, 111.5 109.6, 54.4, 26.4, 20.2, 20.0. UV-vis-NIR (THF) $\lambda_{\max }, \mathrm{nm}\left(\varepsilon, \mathrm{M}^{-1} \mathrm{~cm}^{-1}\right): 290$ (37,000); 331 (41600); 428 sh (4590); 500 sh (1900); 619 (845); 762 sh (110). Anal. Calcd for 3, $\mathrm{C}_{52} \mathrm{H}_{80} \mathrm{~N}_{4} \mathrm{O}_{2} \mathrm{P}_{4} \mathrm{Cr}_{2}$ : C 61.16, H 7.90, N 5.49. Found: C 61.02, H 8.01, N 5.46.

\subsection{Structural determinations}

Single crystals of $\mathbf{2}$ were grown from the diffusion of ether into a concentrated THF solution. Single crystals of $\mathbf{3}$ were grown from pentane layered on a concentrated THF solution. A red block of $2(0.40 \times 0.40 \times 0.40 \mathrm{~mm})$ and a brown block of $3(0.20 \times 0.20 \times 0.20 \mathrm{~mm})$ were placed on the tip of a glass capillary and mounted on a Bruker APEX II Platform CCD diffractometer for data collection at 173(2) K. The data collection was carried out using $\mathrm{Mo} \mathrm{K} \alpha$ radiation (graphite monochromator). The data intensities were corrected for absorption and decay (SADABS).[18] Final cell constants were obtained from least-squares fits of all measured reflections. The structures were solved using SHELXS-97 and refined using SHELXL-97.[19,20] In each case, a direct-methods solution was calculated that provided most of the non-hydrogen atoms from the E-map. Full-matrix least-squares/ difference Fourier cycles were performed to locate the remaining non-hydrogen atoms. All of the non-hydrogen atoms were refined with anisotropic displacement parameters. Hydrogen atoms were placed in ideal positions and refined as riding atoms with relative isotropic displacement parameters. Crystallographic data are summarized in Table 1.

Table 1. Crystallographic data for $\mathbf{2}$ and $\mathbf{3}$

\begin{tabular}{lll}
\hline & \multicolumn{1}{c}{$\mathbf{2}$} & \multicolumn{1}{c}{$\mathbf{3}$} \\
\hline empirical formula & $\mathrm{C}_{26} \mathrm{H}_{40} \mathrm{ClCrN}_{2} \mathrm{OP}_{2}$ & $\mathrm{C}_{26} \mathrm{H}_{40} \mathrm{CrN}_{2} \mathrm{OP}_{2}$ \\
formula weight & 545.99 & 510.54 \\
temperature & $173(2) \mathrm{K}$ & $173(2) \mathrm{K}$ \\
wavelength & $0.71073 \AA$ & $0.71073 \AA$ \\
crystal system & trigonal & monoclinic \\
space group & $\mathrm{R} \overline{3}$ & $\mathrm{C} 2 / \mathrm{c}$ \\
$a(\AA)$ & $21.6460(14)$ & $21.9632(13)$ \\
$b(\AA)$ & $21.6460(14)$ & $10.9312(7)$ \\
$c(\AA)$ & $37.995(3)$ & $22.4127(14)$ \\
$\alpha\left({ }^{\circ}\right)$ & 90 & 90 \\
$\beta\left({ }^{\circ}\right)$ & 90 & $109.9460(10)$ \\
$\gamma\left({ }^{\circ}\right)$ & 120 & 90
\end{tabular}




\begin{tabular}{lll}
\hline $\mathrm{V}\left(\AA^{3}\right)$ & $15417(2)$ & $5058.2(5)$ \\
$Z$ & 9 & 8 \\
$\mathrm{D}_{\text {calcd }}\left(\mathrm{g} \mathrm{cm}^{-3}\right)$ & 1.059 & 1.341 \\
$\theta$ range $\left(^{\circ}\right)$ & 1.882 to 25.052 & 1.93 to 27.45 \\
reflections collected & 47661 & 28127 \\
independent reflections & $6084[R(\mathrm{int})=0.0228]$ & $5762[R(\mathrm{int})=0.0224]$ \\
data / restraints / parameters & $6084 / 25 / 317$ & $5762 / 0 / 297$ \\
goodness-of-fit on $F^{2}$ & 1.132 & 1.046 \\
$R_{1}, w R_{2}(I>2 \sigma(I))$ & $0.0499,0.1543$ & $0.0273,0.0746$ \\
\hline
\end{tabular}

\subsection{Computational Methods}

Geometry optimizations of $\mathbf{3}$ gave unrealistically short $\mathrm{Cr}-\mathrm{Cr}$ bond lengths (1.60 to $1.83 \AA$; experimental $2.13 \AA$ ) despite the use of various functionals (PBE, M06L) and basis sets (def2-TZVP with SDD, aug-cc-pvtz). The full molecule 3 was optimized by constraining the $\mathrm{Cr}-\mathrm{Cr}$ bond distance to $2.13 \AA$, while allowing the ligand atoms to relax. Kohn-Sham density functional theory (KS-DFT) calculations were performed using the Gaussian 09 program package.[21] The M06L functional [22] was used with def2-TZVP basis set on $\mathrm{Cr}, \mathrm{N}, \mathrm{O}$, and $\mathrm{P}$ atoms and def2-SVP basis set on $\mathrm{C}$ and H.[23] No symmetry constraints were imposed on the structure and once the SCF convergence was achieved, a stability check was performed using the 'stable=opt' keyword.[24,25]

In addition to KS-DFT calculations, the electronic structure was further investigated using complete active space self-consistent field (CASSCF) calculations on the M06L-optimized structure using the Molcas 7.8 package.[26-29] The relativistic all-electron ANO-RCC basis sets were used for all elements.[30,31] In all of these calculations, the ANO-RCC-VDZP basis set was used for N, O, P, and Cr, and the ANO-RCC-MB basis set was used for $\mathrm{C}$ and $\mathrm{H}$ atoms.[30,31] The following contractions were used: [5s4p2d1f] for metals, [4s3p1d] for P, [3s2p1d] for $\mathrm{N}$ and $\mathrm{O},[2 \mathrm{~s} 1 \mathrm{p}$ ] for $\mathrm{C}$, and [1s] for $\mathrm{H}$. Additionally, the Cholesky decomposition technique was used combined with local exchange screening to reduce the computational costs involved in generating the two-electron integrals.[32-34]

The chosen active spaces used for $\mathbf{3}$ consisted of eight valence $3 \mathrm{~d}$-electrons in ten $3 \mathrm{~d}$-orbitals plus the empty correlating $4 \mathrm{~d}$-shell, ranging from zero $(8,10)$ to ten $4 \mathrm{~d}$-orbitals $(8,20)$. The natural orbital occupation numbers were used for the evaluations of the effective bond order (EBO), which was calculated as the difference between the total occupancies of the bonding and antibonding molecular orbitals of the metal-metal bond divided by $2 .[35,36]$

\section{Results and discussion}

\section{Synthesis}

The ligand bis(2-((diispropylphosphino)methylamino)phenyl)ether (1), abbreviated as $\mathrm{H}_{2}(\mathrm{PNONP})$, was obtained in one step by heating bis(2-amino-phenyl)ether and 1.95 equiv ${ }^{\mathrm{i}} \mathrm{Pr}_{2} \mathrm{PCH}_{2} \mathrm{OH}$ in $\mathrm{THF}$ at $65^{\circ} \mathrm{C}$ for $12 \mathrm{~h}$ (Scheme 1). The amount of ${ }^{\mathrm{i}} \mathrm{Pr}_{2} \mathrm{PCH}_{2} \mathrm{OH}$ used in the reaction was slightly less than stoichiometric to prevent the formation of the tris-substituted byproduct. The crude product was purified by eluting through a silica plug, giving clean $\mathrm{H}_{2}(\mathrm{PNONP})$ as a clear viscous oil in good yield $(3.1 \mathrm{~g}, 78 \%)$. 


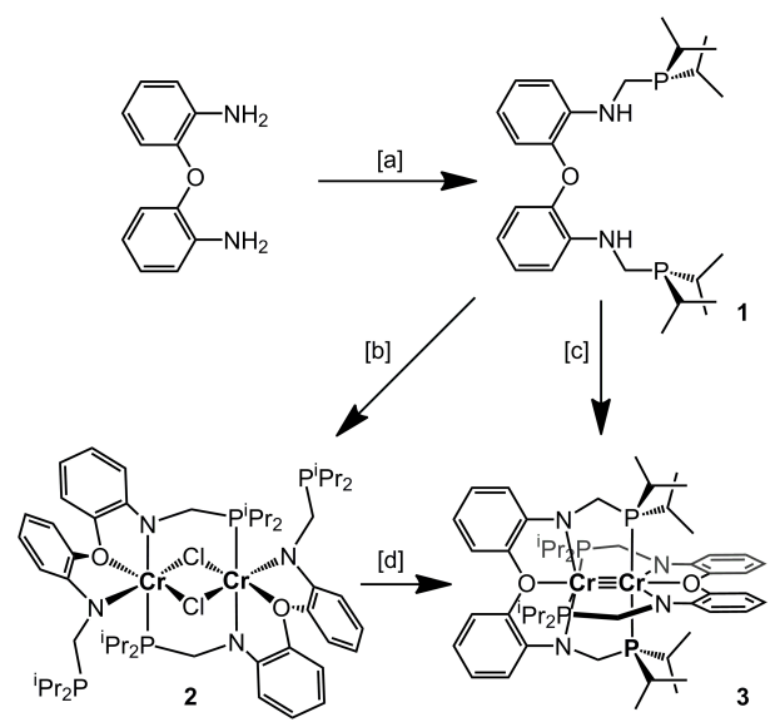

Scheme 1. Synthesis of the ligand, $\mathrm{H}_{2}(\mathrm{PNONP})(\mathbf{1})$, and the dinuclear Cr complexes, 2 and $\mathbf{3}$.

[a] $1.95{ }^{i} \mathrm{Pr}_{2} \mathrm{PCH}_{2} \mathrm{OH}, \mathrm{THF}, 6{ }^{\circ} \mathrm{C}, 12 \mathrm{~h}$; [b] i) $2{ }^{n} \mathrm{BuLi}_{2} \mathrm{Et}_{2} \mathrm{O},-196{ }^{\circ} \mathrm{C}$ to rt, $2 \mathrm{~h}$; ii) $\mathrm{CrCl}_{3}(\mathrm{THF})_{3}, \mathrm{THF},-50{ }^{\circ} \mathrm{C}$ to rt, $12 \mathrm{~h}$; [c] i) $2{ }^{n} \mathrm{BuLi}, \mathrm{Et}_{2} \mathrm{O},-196{ }^{\circ} \mathrm{C}$ to rt, $2 \mathrm{~h}$; ii) $\mathrm{CrCl}_{2}$, THF, $-50^{\circ} \mathrm{C}$ to rt, $12 \mathrm{~h}$; [d] $2 \mathrm{KC}_{8}, \mathrm{THF},-78^{\circ} \mathrm{C}, 3 \mathrm{~h}$.

In the metallation reactions, $\mathrm{H}_{2}$ (PNONP) was deprotonated with 2 equiv. of ${ }^{n} \mathrm{BuLi}$, followed by metathesis with either $\mathrm{CrCl}_{3}$ or $\mathrm{CrCl}_{2}$. In both reactions, dinuclear chromium complexes were generated, as shown in Scheme 1. Using $\mathrm{CrCl}_{3}(\mathrm{THF})_{3}$ as the metal precursor, the orange-red bis( $\mu$-chloride)dichromium(III) complex, $[\mathrm{Cr}(\mu$ $\mathrm{Cl})(\mathrm{PNONP})]_{2}$ (2), was isolated in moderate yield (55\%). Switching to $\mathrm{CrCl}_{2}$, the green-yellow dichromium(II) complex, $[\mathrm{Cr}(\mathrm{PNONP})]_{2}$ (3), was produced featuring multiple bonds between the metal atoms (70\% yield). Complex 3 can also be cleanly formed by reducing 2 with two equiv. $\mathrm{KC}_{8}$.

\section{Molecular Structures}

X-ray diffraction studies were conducted on single crystals of $\mathbf{2}$ and $\mathbf{3}$ to determine their molecular structures. The structure of $\mathbf{2}$ is $C_{i}$ symmetric where the (PNONP) ${ }^{2-}$ ligands, the chromium centers, and the bridging chlorides are related by an inversion center in the $\mathrm{Cr}_{2}(\mu-\mathrm{Cl})_{2}$ core (Fig. 1). Each chromium center is octahedral with a facial coordination of the $N, O, N^{\prime}$-donors in the ligand backbone. The remaining three donors are the two bridging chlorides and a single phosphine. The other phosphine is unligated and is disordered in the crystal lattice. The structure of $\mathbf{2}$ is not particularly remarkable, except that the $\mathrm{Cr}-\mathrm{P}$ bond distance of 2.581(1) $\AA$ is quite long (Table 2). A search of the Cambridge Structural Database (CSD) for $\mathrm{Cr}_{2}(\mu-\mathrm{Cl})_{2}$ cores with a phosphine ligand reveals that the average $\mathrm{Cr}-\mathrm{P}$ bond distance is $2.47 \AA$. [37] Only one other complex, $\left[\mathrm{Cr}(\mu-\mathrm{Cl}) \mathrm{Cl}_{2}\left(\mathrm{Ph}_{2} \mathrm{PNPhPPh}_{2}\right)\right]_{2}$, has a similarly long $\mathrm{Cr}-\mathrm{P}$ bond distance of 2.578(2) $\AA$.[38] Considering that other $\mathrm{Cr}_{2}(\mu-\mathrm{Cl})_{2}$ complexes are equally split between being 6- or 5-coordinate, the weak $\mathrm{Cr}-\mathrm{P}$ interaction in $\mathbf{2}$ is reasonable, especially since the phosphine donor is trans to an amide donor. The trans influence of the other amide donor is also observed in the 
elongation of the $\mathrm{Cr}-\mathrm{Cl}$ bond by $0.13 \AA$ when trans to the amide versus ether donor. Finally, no metal-metal interactions are present in $\mathbf{2}$ as the $\mathrm{Cr} \cdots \mathrm{Cr}$ distance of $3.197 \AA$ is far too long.

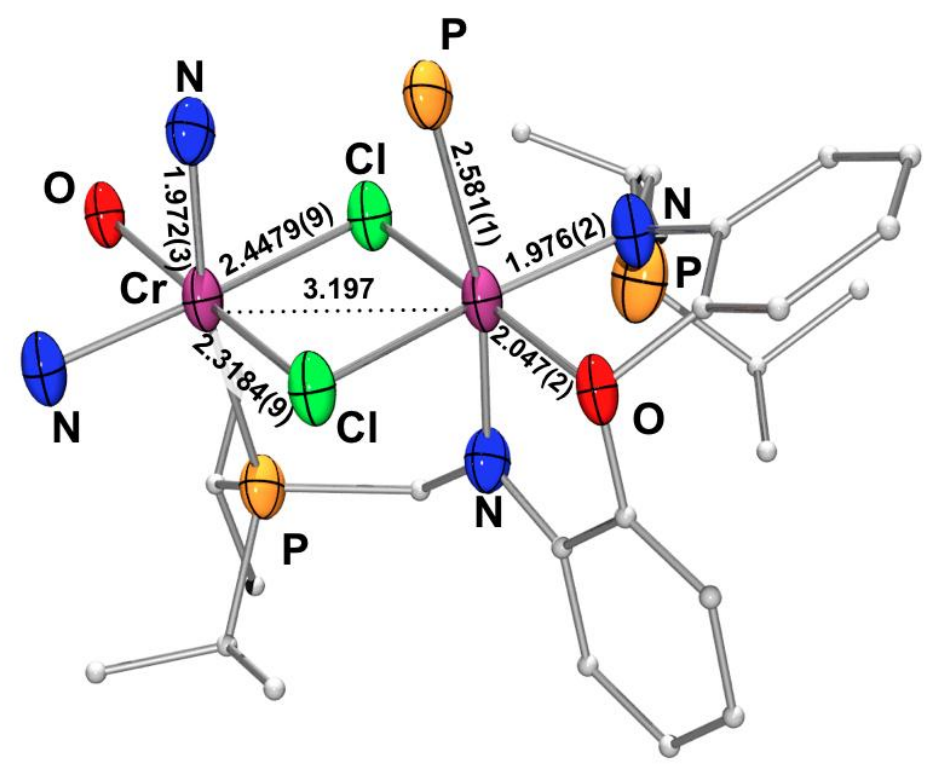

Figure 1. Solid-state structure of the core of dinuclear 2 by $\mathrm{X}$-ray crystallography at $173 \mathrm{~K}$. Thermal ellipsoids are shown at $50 \%$ probability for atoms in the first coordination sphere only. For clarity, only one of the two ligands is shown, and hydrogen atoms are omitted. See SI for full structure.

Table 2. Selected bond lengths and angles for $\mathbf{2}$ and $\mathbf{3}$

\begin{tabular}{lcc}
\hline & $\mathbf{2}$ & $\mathbf{3}$ \\
\hline $\mathrm{Cr} \cdots \mathrm{Cr}$ & $3.197(2)$ & $2.1342(5)$ \\
$\mathrm{FSR}^{\mathrm{a}}$ & 1.36 & 0.91 \\
$\mathrm{Cr}-\mathrm{N}$ & $1.972(3), 1.976(2)$ & $2.026(1), 2.045(1)$ \\
$\mathrm{Cr}-\mathrm{O}$ & $2.047(2)$ & $2.239(1)$ \\
$\mathrm{Cr}-\mathrm{P}$ & $2.581(1)$ & $2.5568(5), 2.5742(5)$ \\
$\mathrm{Cr}-\mathrm{Cl}$ & $2.3184(9), 2.4479(9)$ & - \\
$\mathrm{N}-\mathrm{Cr}-\mathrm{N}\left(^{\circ}\right)$ & $99.3(1)$ & $148.20(5)$ \\
$\mathrm{P}-\mathrm{Cr}-\mathrm{P}\left(^{\circ}\right)$ & - & $173.24(2)$ \\
\hline${ }^{a} \mathrm{Formal}$ shortness ratio (FSR) is the ratio of the $\mathrm{Cr} \cdots$ Cr distance to the sum of their single-bond radii.[39]
\end{tabular}

The molecular structure of $\mathbf{3}$ is shown in Fig. 2. The molecule has approximate $D_{2 d}$ symmetry, with two perpendicular $C_{2}$ axes that bisect the $\mathrm{Cr}-\mathrm{Cr}$ bond and cut between the paddlewheels (Fig. 2b). The chromium atoms are closely bonded to one another with an apical ether donor trans to the metal-metal bond. The $N, O, N^{\prime}-$ donors in the ligand backbone coordinate meridionally. Both ligand arms span across the metal-metal bond, so that the phosphine donors of one ligand coordinate the other $\mathrm{Cr}$ center in a trans manner with $\mathrm{P}-\mathrm{Cr}-\mathrm{P}$ bond angles of $173.24(2)^{\circ}$. By contrast, the amide donors deviate from linearity, with an $\mathrm{N}-\mathrm{Cr}-\mathrm{N}$ angle of $148.20(5)^{\circ}$. 


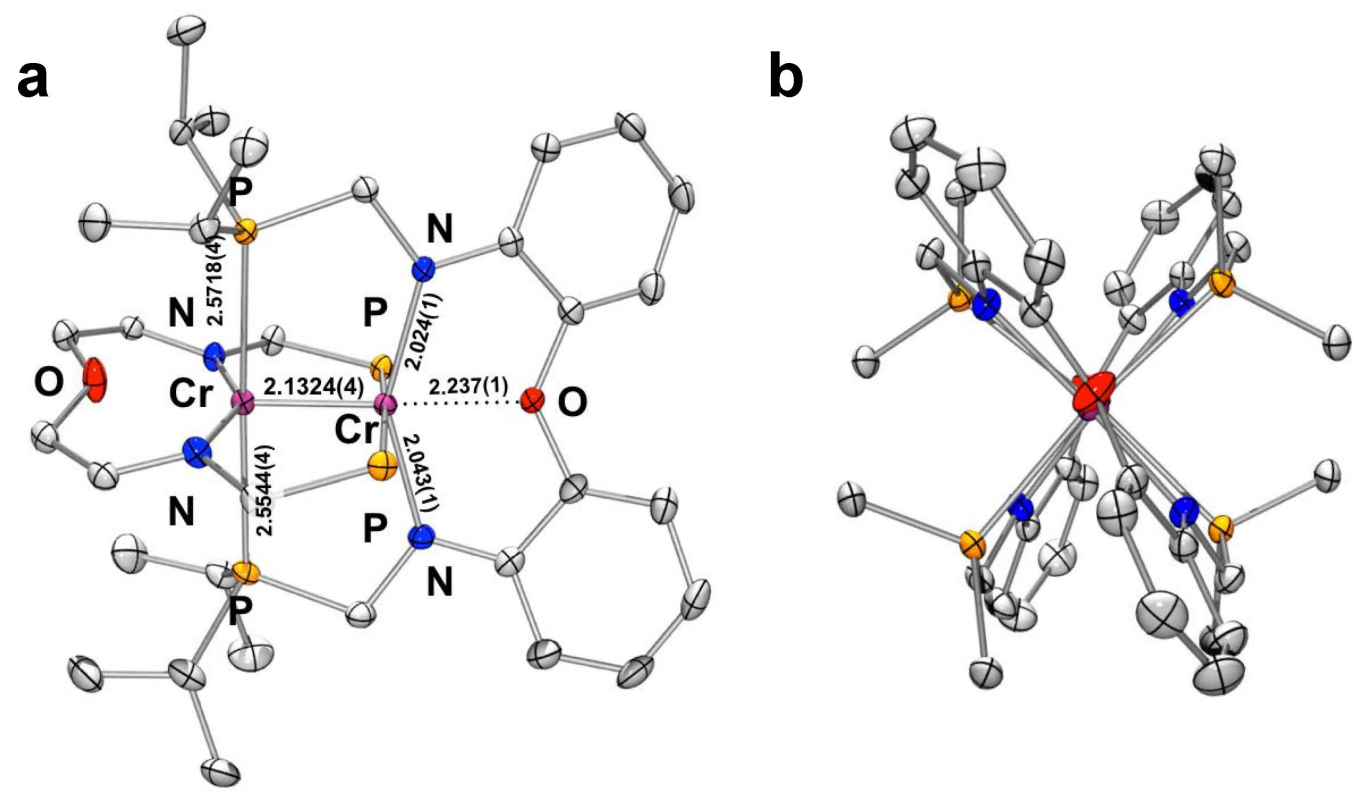

Figure 2. Two views of the solid-state structure of $[\mathrm{PNONPCr}]_{2} \mathbf{3}$ (50\% probability level). View a is perpendicular to the $\mathrm{Cr}-\mathrm{Cr}$ bond axis, and view $\mathbf{b}$ looks down the bond axis. For clarity, only one of the two ligands is fully shown. Hydrogen atoms are omitted for clarity. See SI for full structure.

The $\mathrm{Cr}-\mathrm{Cr}$ bond distance of 2.1324(4) $\AA$ has a formal shortness ratio (FSR) of 0.91 (Table 2).[1] Dichromium paddlewheels show a wide range of $\mathrm{Cr}-\mathrm{Cr}$ bond distances (1.8 to $2.7 \AA$ ), but typically, $<2.0 \AA$ is considered the safe limit for quadruple bonds.[1] Indeed, the $\mathrm{Cr}-\mathrm{Cr}$ bond in $\mathbf{3}$ is longer than other dichromium paddlewheels with similar $N$ - or $P$-donors. For example, the $\mathrm{Cr}$ - $\mathrm{Cr}$ bond length in $\mathrm{Cr}_{2}(\operatorname{map})_{4}$, where map is 2amino-6-methylpyridine, and in $\mathrm{Li}_{2} \mathrm{Cr}_{2}\left(\mathrm{Me}_{2} \mathrm{PCH}_{2}\right)_{6}$ are 1.870(3) and 1.950(2) $\AA$, respectively.[40].[9] The long $\mathrm{Cr}-\mathrm{Cr}$ bond in $\mathbf{3}$ is most likely attributed to the trans ether donors, as $\mathrm{Cr}-\mathrm{Cr}$ bonds in paddlewheel geometries are well known to elongate in the presence of axial donors. Not surprisingly, the $\mathrm{Cr}-\mathrm{Cr}$ bond in $\mathbf{3}$ is quite close to the $\mathrm{Cr}_{2}$ paddlewheel, $\mathrm{Cr}_{2}\left(N, N^{\prime}\right.$-bis(2-methoxyphenyl)formamidinate) ${ }_{4}(2.140(2) \AA)$, wherein two of the tethered methoxy groups can coordinate the $\mathrm{Cr}$ center in the apical positions.[41] $\mathrm{The} \mathrm{Cr} \cdots \mathrm{O}$ distances in this paddlewheel are 2.4 and $2.6 \AA$, which are significantly longer than the $\mathrm{Cr}-\mathrm{O}$ bond length of 2.237(1) $\AA$ in $\mathbf{3}$. The strong dative interactions in $\mathbf{3}$ likely disrupt quadruple bonding between the metal centers. Finally, the $\mathrm{Cr}-\mathrm{P}$ bond lengths (2.5544(4) and 2.5718(4) $\AA$ ) in 3 are considerably longer than those found in $\operatorname{Li}_{2} \mathrm{Cr}_{2}\left(\mathrm{Me}_{2} \mathrm{PCH}_{2}\right)_{6}(2.395(1) \AA)$, but is similar to those in $\mathbf{2}$, suggesting weak $\mathrm{Cr}-\mathrm{P}$ interactions.

\section{NMR Studies}

The ${ }^{1} \mathrm{H}$ NMR spectrum of the ligand 1 in $\mathrm{C}_{6} \mathrm{D}_{6}$ displays 9 resonances, which is one more than the 8 unique protons that were expected: 4 aryl protons, $1 \mathrm{NH}, 1$ methylene, 1 methine, and 1 methyl group. The discrepancy arises from the presence of two methyl peaks, suggesting that the isopropyl groups are locked on the NMR 
timescale and consistent with a solution-state structure that has $C_{2 h}$ symmetry. We speculate that intramolecular hydrogen bonds between the phosphine donors and the amine protons may restrict the movement and/or rotation of the $\mathrm{P}-\mathrm{C}$ bonds. The ${ }^{31} \mathrm{P}$ NMR spectrum of $\mathbf{1}$ consists of a single sharp peak at $2.4 \mathrm{ppm}$.

The ${ }^{1} \mathrm{H}$ NMR spectrum of 2 in $\mathrm{C}_{6} \mathrm{D}_{6}$ is paramagnetic with 8 broad resonances between 68 and -27 ppm, which corresponds to either two-fold or mirror symmetry of the ligand. Compared to the $C_{i}$ symmetry of 2 in the solid state, the solution-state structure has higher symmetry, suggesting that the bound and dangling phosphine donors are undergoing fast exchange relative to the NMR timescale. The fluxional process would also have to invert the two aryl rings in the ligand backbone. Deligation of the bound phosphine could allow the ligand backbone to twist in a turnstile manner, so that the aryl rings exchange, prior to coordination of the other phosphine.

The ${ }^{1} \mathrm{H}$ NMR spectrum of $\mathbf{3}$ in $\mathrm{C}_{6} \mathrm{D}_{6}$ is diamagnetic with 8 sharp resonances, which is consistent with $D_{2 d}$ symmetry in the solid-state and in solution. The methylene peak is notably shifted downfield to 2.19 ppm (compared to $1.60 \mathrm{ppm}$ in 1), which is likely due to deshielding by the ring current of the $\mathrm{Cr}-\mathrm{Cr}$ multiple bond (vide infra). To determine if the phosphine can dissociate in $\mathbf{3}$ as in $\mathbf{2}$ (both have similarly long Cr-P bond lengths), complex 3 was further investigated by variable temperature NMR spectroscopy. Over a wide temperature range from $-80^{\circ}$ to $80^{\circ} \mathrm{C}$, the phosphorus peak shifts upfield from 24.2 to $16 \mathrm{ppm}$ and shows significant peak broadening with increasing temperature (Fig. 3). In this same temperature window, the changes in the ${ }^{1} \mathrm{H}$ NMR spectra are minimal, with only slight broadening of peaks above $80^{\circ} \mathrm{C}$ (SI Figure 9). Similar ${ }^{31} \mathrm{P}$ NMR observations (broadening and upfield shifting ${ }^{31} \mathrm{P}$ peaks at elevated temperatures) have been made in a series of $\mathrm{M}_{2} \mathrm{X}_{4}(\mathrm{PP})_{2}(\mathrm{M}=$ $\mathrm{Mo}, \mathrm{W}$ ) complexes, the cause of which was thought to be observation of a singlet-triplet gap, though no magnetic measurements were reported for these complexes.[10] 

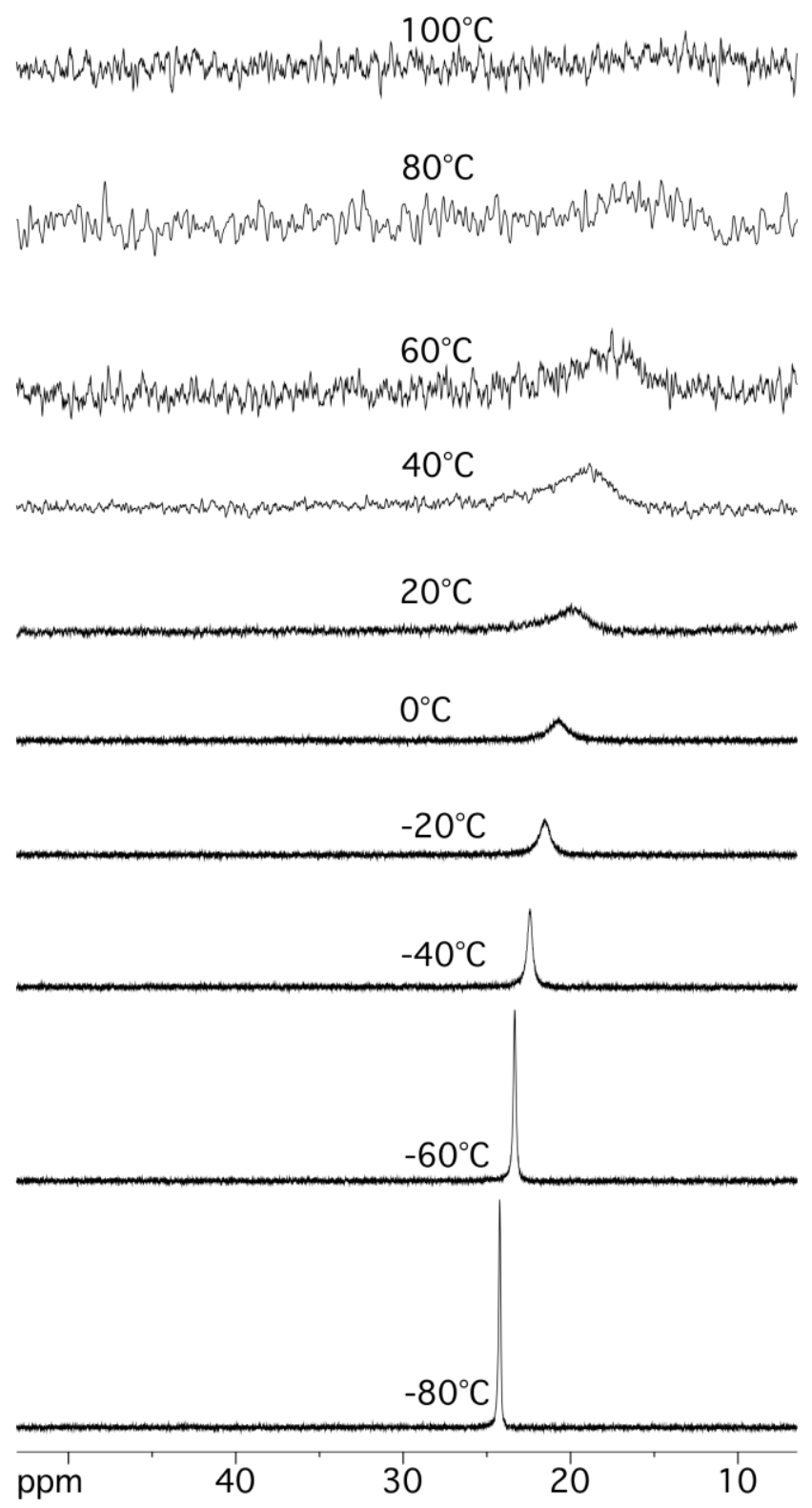

Figure 3. Stacked ${ }^{31} \mathrm{P}$ VT-NMR plot of $3\left(\mathrm{THF}_{8} \mathrm{~d}_{8},-80^{\circ}\right.$ to $\left.100^{\circ} \mathrm{C}\right)$. At each temperature, the position and integration of the peak was determined against an internal reference of $85 \% \mathrm{H}_{3} \mathrm{PO}_{4}$ at temperatures above $0{ }^{\circ} \mathrm{C}$ and $\mathrm{PPh}_{3}$ in toluene at temperatures below $0^{\circ} \mathrm{C}$.

Dichromium paddlewheels can exhibit weak paramagnetism at $\mathrm{rt}$ as a result of a small energy gap between the singlet and triplet states. The singlet-triplet energy gaps have even been estimated by analyzing ${ }^{1} \mathrm{H}$ NMR shifts as a function of temperature.[42] To determine if the triplet excited state is thermally accessible for $\mathbf{3}$, the magnetic susceptibility was measured from 4 to $290 \mathrm{~K}$ (SI Figure 20). At $290 \mathrm{~K}$, a minute magnetic moment of $0.68 \mu_{\mathrm{B}}$ was measured, which could arise from a low-lying paramagnetic excited state. However, diamagnetic compounds can 
exhibit weak paramagnetism under an applied magnetic field; and indeed, the magnetic susceptibility plot of $\mathbf{3}$ was well modeled by using only a temperature-independent paramagnetism term (TIP $=180 \times 10^{-6} \mathrm{emu}$ ). Moreover, in the case of 3 , the ${ }^{1} \mathrm{H}$ NMR peak shifts are invariant with temperature, discounting an energetically low-lying paramagnetic state.

We hypothesize the ${ }^{31} \mathrm{P}$ VT-NMR behavior in $\mathbf{3}$ is due to an equilibrium process involving fast $\mathrm{Cr}-\mathrm{P}$ bond breakage and formation on the NMR timescale. The long $\mathrm{Cr}-\mathrm{P}$ bond distance in the solid-state structure of $\mathbf{3}$ would be consistent with this hypothesis. At low temperature, the intact $\mathrm{Cr}-\mathrm{P}$ bonds give rise to a single, sharp phosphorus peak at $24.2 \mathrm{ppm}$. The broadening of the peak at higher temperature results from a mixture of states where each phosphine is ligated or deligated. As the free ligand resonates at $2.4 \mathrm{ppm}$, it is consistent that the phosphorus peak shifts upfield with increasing temperature. We attempted to test this hypothesis by adding 8 equiv. $\mathrm{PMe}_{3}$ to 3 in $\mathrm{C}_{6} \mathrm{D}_{6}$. Although the ${ }^{31} \mathrm{P}$ peaks for 3 and $\mathrm{PMe}_{3}$ do not shift, both peaks are significantly broadened, which does suggest interaction of $\mathrm{PMe}_{3}$ with $\mathbf{3}$ (SI Figure 8).

Metal-metal multiple bonds are known to exhibit diamagnetic anisotropy $(\Delta \chi),[43]$ and indeed, the methylene resonances for $\mathbf{3}$ are notably shifted downfield. The diamagnetic anisotropy can be calculated using equation 1: (Eq. 1) $\Delta \sigma_{i}=\left(\frac{1}{3 r^{3}}\right) \frac{(\Delta x)\left(1-3 \cos ^{2}(\theta)\right)}{4 \pi}$,[44] where $\Delta \sigma_{i}$ is the difference in chemical shifts of the methylene protons in 3 (4.30 ppm) versus a suitable reference, such as the deprotonated ligand $\mathrm{Li}_{2}(\mathrm{PNONP})(3.46$ ppm). The remaining variables were extracted from the solid-state structure, where $r$ is the average distance and $\theta$ is the average acute angle of the protons relative to the center and axis of the metal-metal bond, respectively. Compared to other dichromium paddlewheel complexes (Table 3), the diamagnetic anisotropy of $\mathbf{3}$ is quite low. Notably, its $\Delta \chi$ is half the value reported for the tetraformamidinate dichromium complex, $\mathrm{Cr}_{2}((p-$ $\left.\left.\mathrm{CH}_{3} \mathrm{C}_{6} \mathrm{H}_{4} \mathrm{~N}\right)_{2} \mathrm{CH}\right)_{4}$.[45] The low diamagnetic anisotropy of $\mathbf{3}$ probably arises from the fewer number of $\mathrm{Cr}-\mathrm{Cr}$ bonding electrons, which is consistent with its longer $\mathrm{Cr}-\mathrm{Cr}$ bond length and lower than quadruple bond order. On the other hand, the diamagnetic anisotropies reported for a family of dichromium tetraformamidinates appear to depend more on the electronics of the aryl rings rather than $\mathrm{Cr}-\mathrm{Cr}$ bond distances, which all fall within a tight range between 1.90 and $1.93 \AA$ A.[45,46] In particular, the complex $\mathrm{Cr}_{2}\left(\left(3,5-\mathrm{Cl}_{2} \mathrm{C}_{6} \mathrm{H}_{3} \mathrm{~N}\right)_{2} \mathrm{CH}\right)_{4}$, which contains electron-withdrawing substituents, has a similarly low $\Delta \chi$ as $\mathbf{3}$ despite having a significantly shorter $\mathrm{Cr}-\mathrm{Cr}$ bond (1.916(1) $\AA$ ). The small $\Delta \chi$ value of $\mathrm{Cr}_{2}\left(\left(3,5-\mathrm{Cl}_{2} \mathrm{C}_{6} \mathrm{H}_{3} \mathrm{~N}\right)_{2} \mathrm{CH}\right)_{4}$ could be rationalized by considering the effect of the aromatic ring current on the shift of backbone proton. For instance, the backbone proton could possibly be shielded by interacting with the $\pi$-system of the aryl rings, thus countering the deshielding effect of the metal-metal multiple bond. In the case of $\mathbf{3}$, the methylene protons are sufficiently removed from the aryl rings in the ligand backbone, so to eschew this alternative explanation. 
Table 3. Diamagnetic anisotropy $(\Delta \chi)$ values for selected dichromium paddlewheels.

\begin{tabular}{lrrc}
\hline Complex & $\Delta \chi^{\mathrm{a}}$ & $\begin{array}{c}\text { Cr-Cr bond } \\
\text { length }(\AA)\end{array}$ & ref \\
\hline $\mathbf{3}$ & -2536 & $2.1342(5)$ & this \\
$\mathrm{Cr}_{2}\left(\left(p-\mathrm{CH}_{3} \mathrm{C}_{6} \mathrm{H}_{4} \mathrm{~N}\right)_{2} \mathrm{CH}\right)_{4}$ & -5230 & $1.930(2)$ & work \\
$\mathrm{Cr}_{2}\left(\left(p-\mathrm{ClC}_{6} \mathrm{H}_{4} \mathrm{~N}\right)_{2} \mathrm{CH}\right)_{4}$ & -4313 & $1.907(1)$ & {$[46]$} \\
$\mathrm{Cr}_{2}\left(\left(3,5-\mathrm{Cl}_{2} \mathrm{C}_{6} \mathrm{H}{ }_{3} \mathrm{~N}\right)_{2} \mathrm{CH}\right)_{4}$ & -2341 & $1.916(1)$ & {$[46]$} \\
$\mathrm{Cr}_{2}\left(\left(m-\mathrm{CF}_{3} \mathrm{C}_{6} \mathrm{H}_{4} \mathrm{~N}\right)_{2} \mathrm{CH}\right)_{4}$ & -3407 & $1.9018(8)$ & {$[46]$} \\
$\mathrm{Cr}_{2}\left(\left(m-\mathrm{OCH}_{3} \mathrm{C}_{6} \mathrm{H}_{4} \mathrm{~N}\right)_{2} \mathrm{CH}\right)_{4}$ & -4522 & $1.918(1)$ & {$[46]$} \\
\hline${ }^{a}$ Unit of $10^{-36} \mathrm{~m}^{3} \mathrm{molecule}^{-1}$ & & &
\end{tabular}

\section{Cyclic Voltammetry}

Complex 3 shows two reversible redox couples at $E_{1 / 2}=-470$ and $-750 \mathrm{mV}$ versus $\mathrm{FeCp}_{2}{ }^{0 /+}$. The reversibility of these processes $\left(E_{\mathrm{pa}}-E_{\mathrm{pc}}=100 \mathrm{mV}\right.$ for both processes; $i_{\mathrm{pa}} / i_{\mathrm{pc}}=1.14,1.00$ for $\mathbf{3}^{0 /+}$ and $\mathbf{3}^{+/ 2+}$, respectively) suggests the complex may undergo two successive one-electron transfers with minimal structural rearrangement or decomposition (even for slow scan rate of $10 \mathrm{mV} / \mathrm{s}$, SI Figure 13). In general, the redox processes of dichromium paddlewheels are irreversible, and attempts to chemically oxidize the $\mathrm{Cr}_{2}^{4+}$ core result in decomposition, presumably via rupture of the $\mathrm{Cr}-\mathrm{Cr}$ bond.[6] As mentioned above, the $\mathrm{X}$-ray structure of a dinuclear $\mathrm{Cr}(\mathrm{III}) \mathrm{Cr}(\mathrm{III})$ complex, made from oxidizing $\mathrm{Cr}_{2}(\mathrm{dpa})_{4}$ with 2 equiv. AgOTf, revealed a long $\mathrm{Cr} \cdots \mathrm{Cr}$ distance of 3.197(3) A..[8] To our knowledge, the only dichromium paddlewheel that displays any reversible redox processes is the tetraguanidinate complex, $\mathrm{Cr}_{2}(\mathrm{DPPC})_{4}$. In $\mathbf{3}$, the two redox couples are separated by $280 \mathrm{mV}$, which is small compared to the $1.08 \mathrm{~V}$ separation for $\mathrm{Cr}_{2}(\mathrm{DPPC})_{4}$.[6] The comproportionation constant $\left(K_{\mathrm{c}}\right)$ for 3 is $5.66 \times 10^{4}$, which is 14 magnitudes smaller than $\mathrm{Cr}_{2}(\mathrm{DPPC})_{4}\left(K_{\mathrm{c}}=1.85 \times 10^{18}\right)$, meaning that the electronic delocalization in $\mathbf{3}$ is substantially less than in $\mathrm{Cr}_{2}(\mathrm{DPPC})_{4}$. Nonetheless, the $K_{\mathrm{c}}$ value for $\mathbf{3}$ is sufficiently large that isolation of the mixed-valent $\mathrm{Cr}(\mathrm{II}) \mathrm{Cr}(\mathrm{III})$ complex should be feasible.

Unfortunately, attempts to isolate the monocation or dication by chemical oxidation have not yielded any well-characterized compounds to date. Addition of 1 and 2 equiv. $\left[\mathrm{FeCp}_{2}\right]\left[\mathrm{BAr}_{4}{ }_{4}\right]$ did generate new species that were sufficiently stable in solution to allow for in situ characterization. For instance, CV scans were performed on an electrochemical solution of $\mathbf{3}$ after adding 1 and 2 equiv. ferrocenium (Fig. 4). As expected, each equivalent of oxidant shifted the open circuit potential in the positive direction. The general invariance of the redox potentials for the redox trio, $\left[\mathrm{Cr}_{2}(\mathrm{PNONP})_{2}\right]^{0 /+1 /+2}$, indicates that the dinuclear molecule remains intact on the $\mathrm{CV}$ timescale upon both one-electron oxidations. 


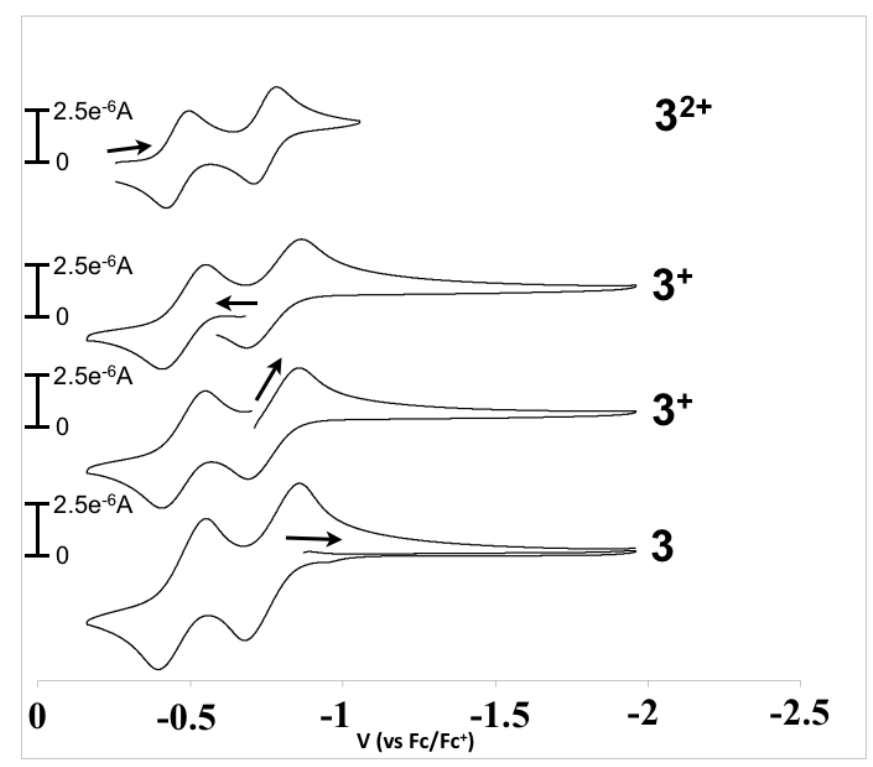

Figure 4. $\mathrm{CV}$ of $\left[\mathrm{Cr}_{2}(\mathrm{PNONP})_{2}\right]^{0 /+1 /+2}\left(\mathbf{3}, \mathbf{3}^{+}\right.$, and $\left.\mathbf{3}^{2+}\right)$ in a $0.4 \mathrm{M}\left[\mathrm{N}^{\mathrm{n}} \mathrm{Bu}_{4}\right] \mathrm{PF}_{6}$ THF solution with a scan rate of 200 $\mathrm{mV} / \mathrm{s}$. Complexes $\mathbf{3}^{+}$and $\mathbf{3}^{2+}$ were generated in situ by adding $\left[\mathrm{FeCp}_{2}\right]\left[\mathrm{BAr}_{4}{ }_{4}\right]$. Potentials were referenced to $\mathrm{FeCp}_{2}{ }^{0 /+}$.

The oxidative processes could be metal and/or ligand centered. As mentioned previously, reversible oxidation(s) for dichromium paddlewheels are rare. To our knowledge, only one $\mathrm{Cr}_{2}{ }^{5+}$ and no $\mathrm{Cr}_{2}{ }^{6+}$ paddlewheel has been structurally characterized.[6,7] Thus, we considered the possibility of ligand-based redox reactivity, where each $\mathrm{PNONP}^{2-}$ ligand in the dimer is oxidized by one electron to the monoanionic radical state, PNONP $^{{ }^{-}}$. To investigate the redox non-innocence of the PNONP ${ }^{2-}$ ligand, we performed $\mathrm{CV}$ on $\mathrm{Li}_{2}(\mathrm{PNONP})$. No oxidative events were observed below $1 \mathrm{~V}$ vs. $\mathrm{FeCp}_{2}{ }^{0 /+}$, suggesting that the ligand is redox innocent below $1 \mathrm{~V}$ (SI Figure 19). In addition, $\mathbf{3}^{+}$was further characterized by X-band EPR spectroscopy (SI Figure 21). An isotropic $S=1 / 2$ signal was observed at $g=1.98$, which is typical for a chromium-based spin, as a ligand-based spin would have $g=$ 2.00. Higher frequency EPR experiments would be needed to definitively assign the metal-character of the spin, as these $g$-values are close to 2.0.[7] Thus, we tentatively assign the redox processes as metal-based oxidations of the $\mathrm{Cr}_{2}{ }^{4+}$ core to $\mathrm{Cr}_{2}{ }^{5+}$ and $\mathrm{Cr}_{2}{ }^{6+}$.

\section{Electronic Absorption Spectroscopy}

The electronic absorption spectra of $\mathbf{3}, \mathbf{3}^{+}$, and $\mathbf{3}^{2+}$, are shown in Figure 5, with the spectral data listed in Table 4. Complex $\mathbf{3}$ has multiple absorptions in the visible range. Of note, two of the spectral features for $\mathbf{3}$ show temperature dependence (SI Figure 14). As the THF solution of 3 is cooled from $0^{\circ} \mathrm{C}$ to $-80{ }^{\circ} \mathrm{C}$, the shoulder at $500 \mathrm{~nm}$ decreases while the band at $619 \mathrm{~nm}$ increases in intensity. Thus, the yellow-green solution at rt turns more intensely green upon cooling. We hypothesize that the color change and the VT ${ }^{31} \mathrm{P}$ NMR behavior are related, 
resulting from a fluxional process where the phosphine arms are labile. We expect the $\delta \rightarrow \delta^{*}$ transition energy to be sensitive to the binding of phosphine donors, as the ligand field energies are directly affected by their interaction with the $\mathrm{Cr}_{2}$ unit. Hence, the band at $619 \mathrm{~nm}$ may be interpreted as the $\delta \rightarrow \delta^{*}$ transition energy of the fully ligated dichromium paddlewheel. This transition energy for $3\left(16,155 \mathrm{~cm}^{-1}\right)$ is low relative to other $\mathrm{Cr}_{2}{ }^{4+}$ paddlewheel complexes, which are typically yellow and have $\delta \rightarrow \delta^{*}$ bands near $450 \mathrm{~nm}\left(\sim 22,000 \mathrm{~cm}^{-1}\right)($ vide infra). The comparison is unsettling because a small $\delta \rightarrow \delta^{*}$ gap would imply an accessible triplet excited state, which would contradict the ${ }^{1} \mathrm{H}$ VT NMR data and the magnetic susceptibility measurements. We thus propose an alternative explanation where because of the longer $\mathrm{Cr}-\mathrm{Cr}$ bond, $\delta$-bonding becomes suppressed and the $d_{\mathrm{xy}}$ orbitals are more localized giving a singlet diradical ground state, i.e. $\left(\mathrm{Cr} d_{\mathrm{xy}}\right)^{1}\left(\mathrm{Cr}^{\prime} d_{\mathrm{xy}}\right)^{1}$. Thus, the low energy band may be more aptly described as a intermetal $d$ - $d$ charge transfer, e.g. $\left(\mathrm{Cr} d_{\mathrm{xy}}\right)^{1}\left(\mathrm{Cr}^{\prime} d_{\mathrm{xy}}\right)^{1} \rightarrow\left(\mathrm{Cr} d_{\mathrm{xy}}\right)^{2}\left(\mathrm{Cr} d_{\mathrm{xy}}\right)^{0}$.

To the best of our knowledge, $\mathrm{Cr}_{2}{ }^{4+}$ paddlewheel complexes with short $\mathrm{Cr}-\mathrm{Cr}$ bond lengths $\leq 2.0 \AA$ only exhibit $\delta \rightarrow \delta^{*}$ transitions between 445 and $490 \mathrm{~nm}\left(22,500-20,800 \mathrm{~cm}^{-1}\right.$ ) (SI Table 1).[6,45,47-49] A few exceptions exist, such as the trimetallic complexes, $\mathrm{Cr}_{2} \mathrm{Fe}(\mathrm{dpa})_{4} \mathrm{Cl}_{2}$ and $\mathrm{Cr}_{2} \mathrm{Zn}(\mathrm{dpa})_{4} \mathrm{Cl}_{2}$.[50,51] The latter complexes are characterized by low-energy transitions at 700 and $697 \mathrm{~nm}\left(14,300\right.$ and $\left.14,600 \mathrm{~cm}^{-1}\right)$, respectively, which is similar to 3 . These transitions were assigned to the $\mathrm{Cr}_{2}{ }^{4+}$ unit. Though the $\mathrm{Cr}-\mathrm{Cr}$ bond lengths are quite short $(2.0 \AA)$, the $\mathrm{N}-\mathrm{Cr}-\mathrm{Cr}-\mathrm{N}$ torsion angles are atypically large at $\sim 20$ degrees. As large torsion angles should also disrupt $\delta$-bonding, we proposed that low-energy bands are the transitions of localized $d_{\mathrm{xy}}$ electrons in the $\mathrm{Cr}_{2}{ }^{4+}$ core.

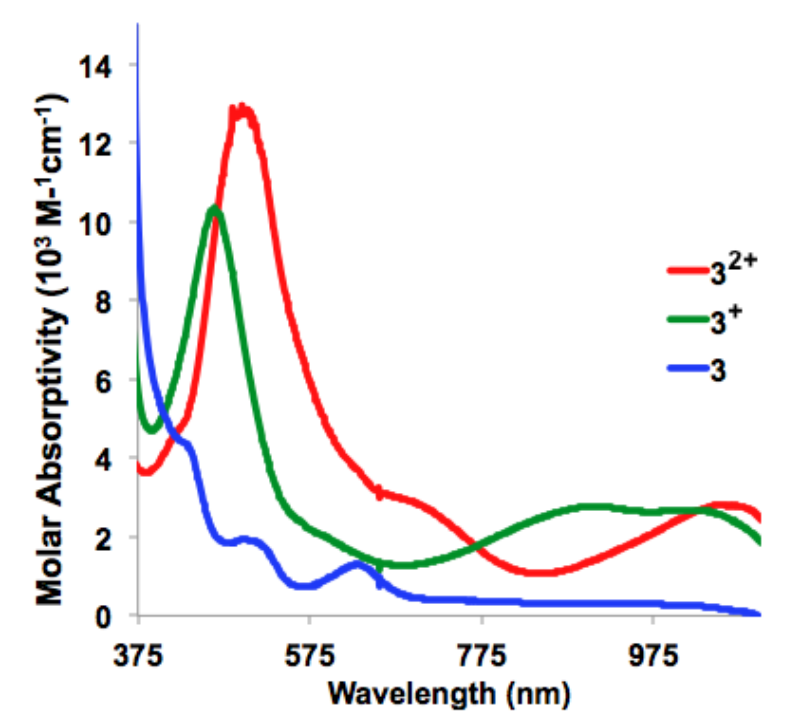

Figure 5. In situ oxidation of $\mathbf{3}$ with $\left[\mathrm{FeCp}_{2}\right]\left[\mathrm{BAr}_{4}^{\mathrm{F}}\right]$ in $\mathrm{THF}$ at $-80^{\circ} \mathrm{C}$, to produce $\mathbf{3}^{+}$, and $\mathbf{3}^{2+}$. The ferrocene byproduct (one and two equivalents, respectively) has a weak absorption at $440 \mathrm{~nm}$, but its intensity $\left(100 \mathrm{M}^{-1} \mathrm{~cm}^{-1}\right)$ is very low. 
The spectral changes between 3 and its oxidized cogeners, $\mathbf{3}^{+}$and $\mathbf{3}^{2+}$, confirm the formation of new species upon in situ oxidation with $\left[\mathrm{FeCp}_{2}\right]\left[\mathrm{BAr}_{4}^{\mathrm{F}}\right]$ at $-80{ }^{\circ} \mathrm{C}$. The most notable change from $\mathbf{3}$ to $\mathbf{3}^{+}$is the appearance of an intense band at $464 \mathrm{~nm}\left(21,550 \mathrm{~cm}^{-1}\right)$, as the solution turns a red-brown color. This band shifts to lower energy $\left(489 \mathrm{~nm}, 20,450 \mathrm{~cm}^{-1}\right.$ ) in $\mathbf{3}^{2+}$. Because of the similarity of this band in both oxidized species, we speculate this is a $\pi \rightarrow \delta$ transition, specifically $\pi^{4} \delta^{1} \rightarrow \pi^{3} \delta^{2}$ in $\mathbf{3}^{+}$and $\pi^{4} \delta^{0} \rightarrow \pi^{3} \delta^{1}$ in $\mathbf{3}^{2+}$. The additional energy needed to overcome electron-electron repulsion in $3^{+}$could account for its higher energy transition relative to $3^{2+}$.

Table 4. Visible electronic absorption data $\left(\lambda_{\max }, \mathrm{nm}\right.$; molar absorptivity in parenthesis, $\left.\mathrm{M}^{-1} \mathrm{~cm}^{-1}\right)$ for $\mathbf{3}, \mathbf{3}^{+}$, and $\mathbf{3}^{2+}$ and selected dichromium paddlewheels.

\begin{tabular}{|c|c|c|}
\hline Complex & $\lambda_{\max }, \mathrm{nm}\left(\boldsymbol{\varepsilon}, \mathrm{L} \mathrm{mol}^{-1} \mathrm{~cm}^{-1}\right)$ & ref \\
\hline 3 & $428 \operatorname{sh}(4590), 500 \operatorname{sh}(1900), 619(845), 762 \operatorname{sh}(110)$ & this work \\
\hline $3^{+}$ & 464 (10000), $580 \mathrm{sh}(2000), 899(2780), 1020(2690)$ & this work \\
\hline $3^{2+}$ & 489 (12700), $690 \mathrm{sh}(2900), 1058(2800)$ & this work \\
\hline $\mathrm{Li}_{4}\left[\mathrm{Cr}_{2}\left(\mathrm{CH}_{3}\right)_{8}\right]$ & $454(700)$ & {$[52]$} \\
\hline $\mathrm{Cr}_{2}(\mathrm{mhp})_{4}^{a}$ & $448(320)$ & {$[48]^{[53]}$} \\
\hline $\mathrm{Cr}_{2}(\mathrm{DPPC})_{4}{ }^{a}$ & $454(980)$ & [6] \\
\hline$\left[\mathrm{Cr}_{2}(\mathrm{DPPC})_{4}\right] \mathrm{PF}_{6}{ }^{a}$ & $435(2200), 580(3200), 752(6800)$ & [6] \\
\hline
\end{tabular}

Theory

To gain insight into the electronic structure and bonding nature of $\mathbf{3}$, KS-DFT and CASSCF studies were conducted. All the calculations were performed on the full molecule, using a geometry optimized structure of $\mathbf{3}$, where only the $\mathrm{Cr}-\mathrm{Cr}$ bond distance was constrained to the experimental value. To address whether diamagnetic 3 is truly a closed-shell singlet or a singlet diradical, ground state energies were computed for both the restricted and unrestricted singlet. The singlet diradical state was found to be lower in energy, by $\sim 36 \mathrm{kcal} / \mathrm{mol}$. The Kohn-Sham molecular orbitals (MOs) of the singlet diradical ground state (SI Figure 22) are consistent with the electronic configuration, $(\pi)^{2}(\pi)^{2}(\sigma)^{2}\left(\mathrm{Cr} d_{\mathrm{xy}}\right)^{1}\left(\mathrm{Cr}^{\prime} d_{\mathrm{xy}}\right)^{1}$, where the chromium atoms are formally triply bonded.[54]

For the CASSCF calculations on 3, two active spaces were investigated (see Experimental Section 2.6), each containing 8 valence electrons in either ten $3 d$-orbitals (10 total orbitals) or in ten $3 d$-orbitals plus ten correlating $4 d$ orbitals (20 total). Both calculations yielded similar results. The ground-state wavefunction is highly multiconfigurational, as the Hartree-Fock configuration, which is the dominant configuration, accounts for only $23 \%$ of the total wavefunction. The natural bonding orbitals that arise from the CASSCF calculations are shown in Figure 6. They are similar to the DFT Kohn-Sham MOs, but one key difference is that the $d_{\mathrm{xy}}$ orbitals form linear combinations in the CASSCF formulation. The resultant MOs, however, show little to no overlap between the atomic orbitals, making them non-bonding, and they are best described as $\left(\mathrm{Cr} d_{\mathrm{xy}}+\mathrm{Cr}^{\prime} d_{\mathrm{xy}}\right)$ and $\left(\mathrm{Cr} d_{\mathrm{xy}}-\mathrm{Cr}^{\prime} d_{\mathrm{xy}}\right)$, rather than $\delta$ and $\delta^{*}$, respectively. 


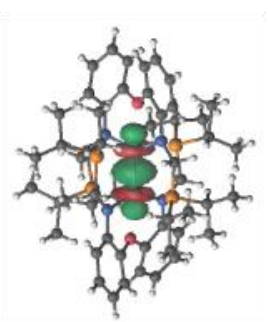

$\sigma(1.66)$

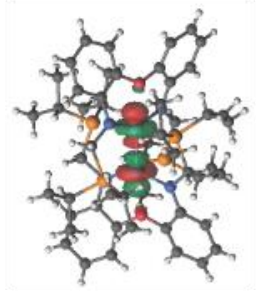

$\sigma^{*}(0.32)$
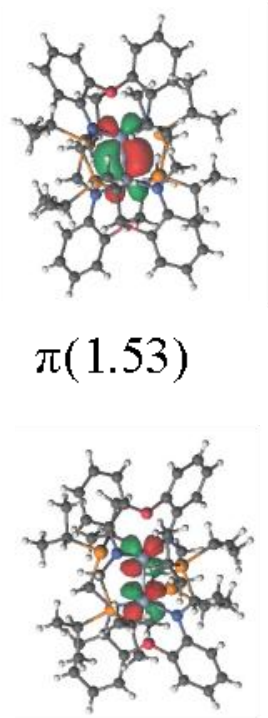

$\pi^{*}(0.45)$
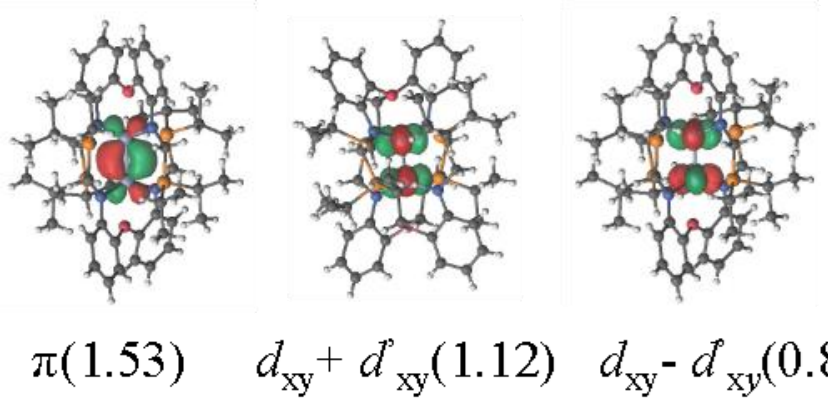

$d_{\mathrm{xy}}-d_{\mathrm{xy}}(0.86)$
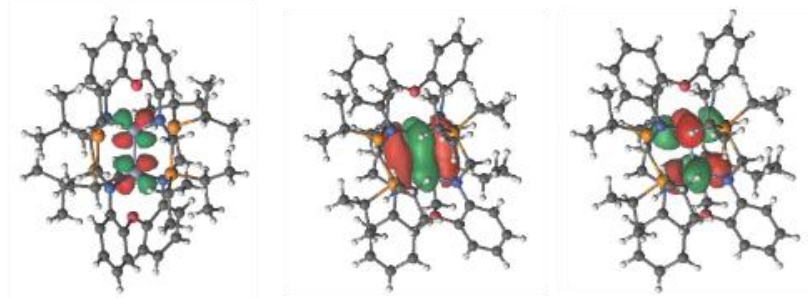

$\pi *(0.46)$

Figure 6. Natural bonding orbitals of $\mathbf{3}$ and their electron occupation numbers.

By considering the total ground-state wavefunction, the natural orbital occupation numbers are: $(\sigma)^{1.66}(\pi)^{1.53}(\pi)^{1.53}\left(\mathrm{Cr} d_{\mathrm{xy}}+\mathrm{Cr}^{\prime} d_{\mathrm{xy}}\right)^{1.12}\left(\mathrm{Cr} d_{\mathrm{xy}}-\mathrm{Cr}^{\prime} d_{\mathrm{xy}}\right)^{0.86}\left(\pi^{*}\right)^{0.46}\left(\pi^{*}\right)^{0.45}\left(\sigma^{*}\right)^{0.32}$. The partial occupation of antibonding orbitals decreases the effective metal-metal bond order to 1.9, which is consistent with the long $\mathrm{Cr}-\mathrm{Cr}$ bond in $\mathbf{3}$. Moreover, the absence of delta-bonding in $\mathbf{3}$ explains the atypical spectroscopic properties of $\mathbf{3}$ relative to other quadruply bonded dichromium paddlewheels in the literature.[55]

\section{Initial Reactivity}

Preliminary reactivity studies were conducted to determine if the multiply bonded $\mathrm{Cr}_{2}{ }^{4+}$ core of $\mathbf{3}$ could mediate redox reactions. Indeed, the pair of $\mathbf{2}$ and $\mathbf{3}$ was attractive for proton-to- $\mathrm{H}_{2}$ reduction, whereby the $\mathrm{Cr}_{2}{ }^{4+}$ core in 3 reacts with two equiv $\mathrm{HCl}$ to generate $\mathrm{H}_{2}$ and in turn becomes oxidized to 2. Alas, none of these anticipated products were observed, and instead, $\mathrm{HCl}$ merely protonates the ligand to form $\mathrm{H}_{2}(\mathrm{PNONP})$. We also investigated whether 2 could be photolyzed to release $\mathrm{Cl} \bullet\left(\right.$ or $\left.\mathrm{Cl}_{2}\right)$ to generate $\mathbf{3}$, but that was also unsuccessful.

\section{Conclusions}

Dinuclear chromium complexes self-assemble in the metallation reactions of the mixed phosphine-amide-ether donor ligand, $\mathrm{PNONP}^{2-}$, with either $\mathrm{Cr}(\mathrm{II})$ or $\mathrm{Cr}(\mathrm{III})$ chloride reagents. In the case of $\mathrm{Cr}(\mathrm{II})$, the $\mathrm{Cr}_{2}{ }^{4+}$ paddlewheel complex, $\mathrm{Cr}_{2}(\mathrm{PNONP})(3)$, was generated that contains a formal triple $\mathrm{Cr} \equiv \mathrm{Cr}$ bond. The computed electronic structure supports this bonding description, and reveals that two $d$ - 
electrons are non-bonding and are localized at the individual chromium sites. The electronic structure is consistent with the relative long $\mathrm{Cr}-\mathrm{Cr}$ bond length (> $2.0 \AA$ ), which would preclude delta-bonding, and thus, rationalizes the unusually rich electronic absorption spectra of $\mathbf{3}$ relative to other quadruply bonded $\mathrm{Cr}_{2}{ }^{4+}$ species. In addition, $\mathrm{Cr}_{2}(\mathrm{PNONP})$ shows two intriguing redox couples that are reversible on the $\mathrm{CV}$ timescale. We propose that the oxidized members are the mixed-valent $\mathrm{Cr}_{2}{ }^{5+}$ and the $\mathrm{Cr}_{2}{ }^{6+}$ species, but further characterization will be needed to definitively assign their oxidation states.

\section{Acknowledgments}

The authors thank Dr. Eckhard Bill and Andreas Göbels (Max Planck Institute) for their expertise in SQUID data collection, as well as Dr. Victor G. Young, Jr. (UMN) for helpful discussions regarding Xray crystallography. This work was supported in part by the National Science Foundation (CHE-1254621 and CHE-1212575). This material is based upon work supported by the U.S. Department of Energy Office of Science, Office of Basic Energy Sciences Energy Frontier Research Centers program under Award Number DE-SC-0001234. CCL is grateful to the Alfred P. Sloan Foundation for a research fellowship. RKC thanks the NSF for a graduate fellowship. KMB was funded by UROP. X-ray diffraction experiments were performed using a crystal diffractometer acquired through an NSF-MRI award (CHE-1229400) in the X-ray laboratory. 


\section{References}

(1) F.A. Cotton In Multiple Bonds Between Metal Atoms; F.A. Cotton, C.A. Murillo, R.A. Walton, Eds.; Springer Science: New York, 2005, p 35.

(2) F.A. Cotton In Multiple Bonds Between Metal Atoms; F.A. Cotton, C.A. Murillo, R.A. Walton, Eds.; Springer Science: New York, 2005, p 1.

(3) A.K. Nair, N.V.S. Harisomayajula, Y.-C. Tsai, Dalton Trans. 2014, 43, 5618.

(4) F.R. Wagner, A. Noor, R. Kempe, Nat. Chem. 2009, 1, 529.

(5) T. Nguyen, A.D. Sutton, M. Brynda, J.C. Fettinger, G.J. Long, P.P. Power, Science 2005, 310, 844 .

(6) F.A. Cotton, L.M. Daniels, P. Huang, C.A. Murillo, Inorg. Chem. 2002, 41, 317.

(7) F.A. Cotton, N.S. Dalal, E.A. Hillard, P. Huang, C.A. Murillo, C.M. Ramsey, Inorg. Chem. 2003, 42, 1388.

(8) D.W. Brogden, Y. Turov, M. Nippe, G. Li Manni, E.A. Hillard, R. Clérac, L. Gagliardi, J.F. Berry, Inorg. Chem. 2014, 53, 4777.

(9) D. Steinborn, O. Neumann, C. Bruhn, T. Rüffer, R. Boese, F.W. Heinemann, Chem. Eur. J. 1998, 4, 2204.

(10) F.A. Cotton, J.L. Eglin, B. Hong, C.A. James, Inorg. Chem. 1993, 32, 2104.

(11) F.A. Cotton, J.L. Eglin, C.A. James, Inorg. Chem. 1993, 32, 681.

(12) O. Kocian, N. Spencer, J. Fraser Stoddart, I. Cragg-Hine, M. Davidson, F.S. Mair, P. Raithby, R. Snaith, T. Kottke, E. Pohl, Tetrahedron 1995, 51, 579.

(13) In Inorganic Syntheses; John Wiley \& Sons, Inc.: 2002, p 75.

(14) D.F. Evans, J. Chem. Soc. 1959, 2003.

(15) C.J. O'Connor In Progress in Inorganic Chemistry; S.J. Lippard, Ed.; John Wiley \& Sons, Inc.: New York, 1982; Vol. 29, p 203.

(16) R.C. Weast, M.J. Astle CRC Handbook of Chemistry and Physics; 59th ed.; CRC Press Inc.: Boca Raton, FL, 1979.

1993.

(17) O. Kahn Molecular Magnetism; VCH Publishers, Inc.: Weinheim, Germany,

(18) G.M. Sheldrick Program SADABS, 1997.

(19) G.M. Sheldrick, T.R. Schneider, Macromol. Crystallogr., Part B 1997, 277, 319.

(20) G. Sheldrick, Acta Crystallogr. Sect. A 2008, 64, 112.

(21) Gaussian 09, Revision D.1, M.J.T. Frisch, G. W.; Schlegel, H. B.; Scuseria, G. E.; Robb, M. A.; Cheeseman, J. R.; Scalmani, G.; Barone, V.; Mennucci, B.; Petersson, G. A.; Nakatsuji, H.; Caricato, M.; Li, X.; Hratchian, H. P.; Izmaylov, A. F.; Bloino, J.; Zheng, G.; Sonnenberg, J. L.; Hada, M.; Ehara, M.; Toyota, K.; Fukuda, R.; Hasegawa, J.; Ishida, M.; Nakajima, T.; Honda, Y.; Kitao, O.; Nakai, H.; Vreven, T.; Montgomery, Jr., J. A.; Peralta, J. E.; Ogliaro, F.; Bearpark, M.; Heyd, J. J.; Brothers, E.; Kudin, K. N.; Staroverov, V. N.; Kobayashi, R.; Normand, J.; Raghavachari, K.; Rendell, A.; Burant, J. C.; Iyengar, S. S.; Tomasi, J.; Cossi, M.; Rega, N.; Millam, J. M.; Klene, M.; Knox, J. E.; Cross, J. B.; Bakken, V.; Adamo, C.; Jaramillo, J.; Gomperts, R.; Stratmann, R. E.; Yazyev, O.; Austin, A. J.; Cammi, R.; Pomelli, C.; Ochterski, J. W.; Martin, R. L.; Morokuma, K.; Zakrzewski, V. G.; Voth, G. A.; Salvador, P.; Dannenberg, J. J.; Dapprich, S.; Daniels, A. D.; Farkas, Ö.; Foresman, J. B.; Ortiz, J. V.; Cioslowski, J.; Fox, D. J. , Gaussian, Inc., Wallingford, CT 2009.

(22) Y. Zhao, D.G. Truhlar, J. Chem. Phys. 2006, 125. 
(23) F. Weigend, R. Ahlrichs, Phys. Chem. Chem. Phys. 2005, 7, 3297.

(24) R. Seeger, J.A. Pople, J. Chem. Phys. 1977, 66, 3045.

(25) R. Bauernschmitt, R. Ahlrichs, J. Chem. Phys. 1996, 104, 9047.

(26) B.O. Roos, P.R. Taylor, P.E.M. Siegbahn, Chem. Phys. 1980, 48, 157.

(27) K. Andersson, P.Å. Malmqvist, B.O. Roos, J. Chem. Phys. 1992, 96, 1218.

(28) K. Andersson, P.Å. Malmqvist, B.O. Roos, A.J. Sadlej, K. Wolinski, J. Phys. Chem. 1990, 94, 5483.

(29) F. Aquilante, L. De Vico, N. Ferré, G. Ghigo, P.-Å. Malmqvist, P. Neogrady, T. Pedersen, M. Pitonak, M. Reiher, B.O. Roos, L. Serrano-Andrés, M. Urban, V. Veryazov, R. Lindh, J. Comput. Chem. 2010, 31, 224.

(30) B.O. Roos, R. Lindh, P.Å. Malmqvist, V. Veryazov, P.O. Widmark, J. Phys. Chem. $A$ 2004, 108, 2851.

(31) B.O. Roos, R. Lindh, P.Å. Malmqvist, V. Veryazov, P.O. Widmark, J. Phys. Chem. A 2005, 109, 6575.

(32) F. Aquilante, P.-A. Malmqvist, T.B. Pedersen, A. Ghosh, B.O. Roos, J. Chem.

Theory Comp. 2008, 4, 694.

(33) F. Aquilante, T.B. Pedersen, R. Lindh, J. Chem. Phys. 2007, 126, 194106.

(34) F. Aquilante, T.B. Pedersen, R. Lindh, B.O. Roos, A.S. de Meras, H. Koch, J. Chem. Phys. 2008, 129, 24113.

(35) M. Brynda, L. Gagliardi, B.O. Roos, Chem. Phys. Lett. 2009, 471, 1.

(36) B.O. Roos, A.C. Borin, L. Gagliardi, Angew. Chem. Int. Ed. 2007, 46, 1469.

(37) F. Allen, Acta Crystallographica Section B 2002, 58, 380.

(38) A. Bollmann, K. Blann, J.T. Dixon, F.M. Hess, E. Killian, H. Maumela, D.S.

McGuinness, D.H. Morgan, A. Neveling, S. Otto, M. Overett, A.M.Z. Slawin, P. Wasserscheid, S. Kuhlmann, J. Am. Chem. Soc. 2004, 126, 14712.

(39) L. Pauling, J. Am. Chem. Soc. 1947, 69, 542.

(40) F.A. Cotton, R.H. Niswander, J.C. Sekutowski, Inorg. Chem. 1978, 17, 3541.

(41) F.A. Cotton, L.M. Daniels, C.A. Murillo, P. Schooler, J. Chem. Soc., Dalton Trans.

2000, 2007.

(42) F.A. Cotton, H. Chen, L.M. Daniels, X. Feng, J. Am. Chem. Soc. 1992, 114, 8980.

(43) J. San Filippo, Inorg. Chem. 1972, 11, 3140.

(44) H.M. McConnell, C.H. Holm, J. Chem. Phys. 1957, 27, 314.

(45) F.A. Cotton, T. Ren, J. Am. Chem. Soc. 1992, 114, 2237.

(46) K.M. Carlson-Day, J.L. Eglin, C. Lin, L.T. Smith, R.J. Staples, D.O. Wipf, Polyhedron 1999, 18, 817.

(47) R. Clerac, F. Albert Cotton, S.P. Jeffery, C.A. Murillo, X. Wang, Dalton Trans. 2003, 3022 .

(48) F.A. Cotton, P.E. Fanwick, R.H. Niswander, J.C. Sekutowski, J. Am. Chem. Soc. 1978, $100,4725$.

(49) A. Belforte, D. Belli Dell'Amico, F. Calderazzo, M. Devillers, U. Englert, Inorg. Chem. 1993, 32, 2282.

(50) M. Nippe, J.F. Berry, J. Am. Chem. Soc. 2007, 129, 12684.

(51) M. Nippe, E. Bill, J.F. Berry, Inorg. Chem. 2011, 50, 7650.

(52) J. Krausse, G. Marx, G. Schödl, J. Organomet. Chem. 1970, 21, 159.

(53) P.E. Fanwick, B.E. Bursten, G.B. Kaufmann, Inorg. Chem. 1985, 24, 1165. 
(54) Orthogonalizing the alpha and beta KS orbitals is a way to calculate the spatial overlap between these singly occupied orbitals. With PBE, there is less than $25 \%$ overlap, suggesting that the orbitals can be well described as localized, singly occupied orbitals.

(55) G. La Macchia, G. Li Manni, T.K. Todorova, M. Brynda, F. Aquilante, B.O. Roos, L. Gagliardi, Inorg. Chem. 2010, 49, 5216. 

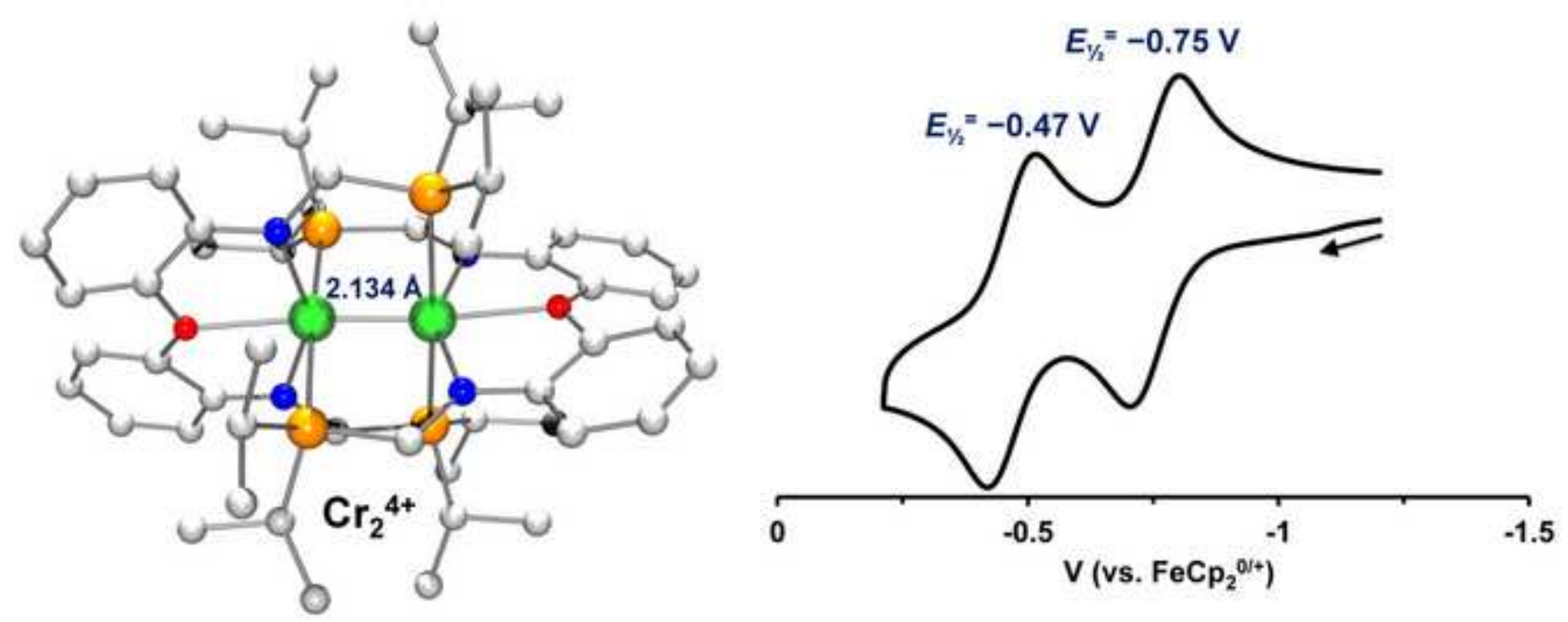